\title{
Lavar, passar e receber visitas: debates sobre a regulamentação da prostituição e experiências de trabalho sexual em Buenos Aires e no Rio de J aneiro, fim do século XIX*
}

Cristiana Schettini Pereira**

Resumo

Este artigo explora os debates em torno da regulamentação da prostituição e algumas experiências de trabalho sexual em Buenos Aires e no Rio de Janeiro, numa perspectiva contrastante. A intenção é evidenciar algumas conexões entre os debates regulamentaristas e os debates sobre as relações de trabalho em ambas cidades no final do século XIX.

Palavras-chave: Prostituição, Escravidão, Rio de J aneiro, Buenos Aires, Século XIX.

\footnotetext{
* Recebido para publicação em maio de 2005, aprovado em julho de 2005.

** Centro de Estudios Latinoamericanos/Universidad Nacional de San Martín Buenos Aires, Argentina e Núcleo de Estudos de Gênero - Pagu/Unicamp, Campinas-SP. C rischettini@gmail.com
} 
Lavar, passar e receber visitas

Laundry, Ironing, and Male Callers:

Debates over the Regulation of Prostitution and Sexual Work

Experiences in Buenos Aires and Rio de J aneiro, end of the $19^{\text {th }}$ Century

\section{Abstract}

This article explores public debates over the regulation of prostitution, as well as experiencies of sexual work in Buenos Aires and in Rio de Janeiro in order to establish some connections between the debates over prostitution and the debates over labor relacions in course in both cities by the end of the $19^{\text {th }}$ Century.

Key Words: Prostitution, Slavery, Rio de J aneiro, Buenos Aires, $19^{\text {th }}$ Century. 
A partir das décadas finais do século 19, o tema do comércio sexual na América do Sul esteve fortemente associado a narrativas de "tráfico de brancas" - histórias de mulheres européias que seriam trazidas por redes internacionais de traficantes para cidades portuárias, onde, sem falar o idioma e sem conhecer ninguém, seriam obrigadas a exercer a prostituição, sendo por isso conhecidas como "escravas brancas". Estes relatos atraíram o interesse de uma parte importante da historiografia sobre o tema, que se concentrou nas histórias de coerção e mobilidade internacional de mulheres européias. Mas para seus contemporâneos sul-americanos, estes relatos se misturavam a uma variedade de outras dimensões do comércio sexual. Em capitais como Buenos Aires e Rio de Janeiro, o tema da prostituição esteve também profundamente misturado aos temas do trabalho doméstico, infantil, à escravidão e outras práticas coercitivas e, conseqüentemente, aos debates sobre a intervenção estatal nas próprias relações de trabalho.

Tanto nas histórias cada vez mais sensacionais sobre um tráfico internacional de mulheres, como nos significados mais locais da prostituição, questões em torno de práticas coercitivas, da liberdade de dispor de si estavam presentes, atingindo a uma variedade de jovens mulheres, crianças e escravas de formas muito concretas. Este artigo explora os debates e algumas experiências de trabalho sexual em Buenos Aires e no Rio de Janeiro, numa perspectiva contrastante, com a intenção de evidenciar suas conexões com os debates sobre relações de trabalho em ambas cidades. A confrontação entre ambos casos amplia a possibilidade de complicar certas dicotomias que agora podem aparentar ser imóveis e excludentes, tal como práticas antigas e modemas, ou trabalho escravo e livre.

No século XIX, os temas da prostituição e da escravidão estiveram vinculados, em diferentes partes do mundo. Na Europa, as metáforas da escravidão serviram, na segunda metade do século XIX, para denunciar a violência que envolvia a crescente mobilidade internacional de prostitutas européias. Mesmo antes, 
Lavar, passar e receber visitas

na Inglaterra dos anos 1830, a expressão "escravidão branca" fazia referência tanto à exploração de mulheres em fábricas como à exploração de jovens judias por homens também judios. ${ }^{1}$ No Rio de Janeiro dos anos 1840, quando os médicos começaram a estudar a prostituição como um "fato social", a escravidão era uma referência obrigatória, e não apenas como metáfora de degradação moral: a maioria das prostitutas na corte imperial brasileira era de escravas negras. $^{2}$

Sobretudo a partir da década de 1870 , as metáforas de escravidão para falar da prostituição de mulheres européias se generalizaram, de modo simultâneo ao deslocamento maciço de trabalhadores europeus para o continente americano. Embora os movimentos operários continuassem empregando as mesmas metáforas para denunciar a exploração capitalista do trabalho feminino e infantil, a expressão "escravidão branca" passou a ser predominantemente associada à prostituição forçada de mulheres européias em outros continentes. Mulheres européias e histórias de "tráfico de brancas" desembarcaram em diferentes partes do mundo, e em cada lugar ganharam dimensões políticas e significados particulares, de acordo com as histórias das relações de trabalho, as configurações de gênero e as práticas locais de comércio sexual.

Em contrapartida a essa circulação internacional de mulheres e histórias de tráfico, muitos países, tanto no continente europeu como no norte-americano, começaram a articular o que uma historiadora denominou como "tráfico internacional de

\footnotetext{
1 BRISTOW, Edward. Prostitution and Prejudice: the Jewish Fight Against White Slavery, 1870-1939. Oxford, Oxford University Press, 1982, pp.35-38.

2 Cunha, Herculano A. Lassance. Dissertação So bre a Prostituição, em Particular na Cidade do Rio de J aneiro. Rio de J aneiro, Tipografia de Paula Brito, 1845. Sobre ele, ver SOARES, Luis Carlos. Rameiras, Ilhoas e Polacas... A Prostituição no Rio de Janeiro do século XIX. São Paulo, Ática, 1992, pp.19-21; e ENGEL, Magali. Meretrizes e doutores: Saber Médico e Prostituição na Cidade do Rio de J aneiro, 1845-1890. São Paulo, Brasiliense, 1990.
} 
políticas de prostituição". Nesse "tráfico" de idéias e políticas, diferentes projetos de regulamentação estatal da prostituição foram debatidos e adotados num marco de relações internacionais desiguais. Embora a historiografia sobre o tema tenda a agrupar essas políticas em dois grupos principais - regulamentaristas e abolicionistas -, o debate principal para os contemporâneos não era tanto entre a presença ou ausência do Estado, e sim até que ponto, e em que termos, os poderes públicos, nacionais e municipais, deveriam ou poderiam intervir em relações sexuais e numa variedade de formas de trabalho doméstico.

Não era por acaso, assim, que o vocabulário empregado para descrever as dinâmicas internacionais da prostituição escravidão branca, tráfico de brancas, abolicionismo - fosse o mesmo utilizado pelos movimentos contra a escravidão africana no ocidente ao largo do século XIX. Enquanto evidenciava as dimensões de violência, imoralidade e coerção, que caracterizariam a prostituição internacional de mulheres européias, esse vocabulário legitimava moralmente a intervenção política de certos grupos a favor das vítimas. ${ }^{4} \mathrm{~A}$ denominação de "escravas brancas" para mulheres européias que se dedicavam à prostituição em outros continentes terminava restringindo-as à condição de vítimas passivas e indefesas, o que predispunha a que qualquer mobilidade ou outra ação delas fosse sempre

\footnotetext{
3 BRIG GS, Laura. Reproducing Empire: Race, Sex, Science and U.S. Imperialism in Puerto Rico. Berkeley/Los Angeles, University of California Press, 2002, pp.21-41.

${ }^{4} \mathrm{O}$ vocabulário da escravidão permitiu às feministas inglesas juntar a campanha abolicionista com a campanha contra a regulamentação da prostituição, que elas associavam ao tráfico de mulheres, como parte de uma mesma "cruzada moral". É o que se percebe pelo obituário de uma delas: "Para ela, foi natural a transição da luta contra a escravidão negra nas Índias Ocidentais e na América do Sul para a luta contra a tentativa de escravizar as mulheres numa vida de vício". apud Walkowitz, J udith. Prostitution and Victorian Society: Women, Class and the State. Cambridge, Cambridge University P ress, 1980, pp.123-124.
} 
Lavar, passar e receber visitas

interpretada em termos de coerção. ${ }^{5}$ Para isso contribuía a aparente oposição irredutível e irreconciliável entre escravidão e liberdade, que ganhava ares de algo natural e auto-evidente em meio às lutas abolicionistas do século XIX. Se por um lado essa operação legitimava a ação política de certas mulheres que falavam publicamente em nome das vítimas, por outro ela também legitimava intervenções estatais, com fins profiláticos e moralizadores, nos comportamentos sexuais de diferentes grupos sociais. ${ }^{6} \mathrm{~A}$ metáfora da escravidão, assim, conferia um sentido de atraso e violência a certas práticas de prostituição, às quais se opunham grupos organizados e os poderes públicos, numa intervenção que buscava ser qualificada de moderna e civilizada.

Outra conseqüência da associação entre a mobilidade internacional de mulheres européias e a prostituição forçada foi 0 encobrimento de outras práticas de prostituição, envolvendo mulheres não-européias. Variadas e complexas experiências de prostituição no período terminavam restritas a uma única modalidade de violência e coerção - aquelas exercidas pelo proxeneta. ${ }^{7}$ Mas tanto em Buenos Aires como no Rio de J aneiro, fontes judiciais revelam que prostitutas argentinas e brasileiras

\footnotetext{
5 Para o caso do Rio de Janeiro, ver Pereira, Cristiana Schettini, "Que Tenhas Teu Corpo": uma história social da prostituição no Rio de J aneiro das primeiras décadas republicanas. Rio de Janeiro, Arquivo Nacional, 2005, (no prelo). Para uma análise semelhante na atualidade, ver PISCITELLI, Adriana. Entre a Praia de Iracema e a União Européia: turismo sexual internacional e migração feminina. In: PIscitellı, Adriana et alii. (orgs.) Sexualidades e Saberes, Convenções e Fronteiras. Rio de J aneiro, Garamond, 2004.

6 Walkowitz, J. Prostitution and Victorian Society... Op. cit; Corbin, Alain. Women for Hire: Prostitution and Sexuality in France after 1850. Cambridge, Mass., Harvard University Press, 1990, p.297; ODEM, Mary El. Delinquent Daughters: Protecting and Policing Adolescent Female Sexuality in the United States, 1885-1920. Chapel Hill, University of North Carolina Press, 1995.

7 Donna Guy desenvolve esse ponto em GuY, Donna. Medical Imperialism gone Awry: the campaign against legalized prostitution in Latin America. In: MEADE, Teresa et alii. Science, Medicine and Cultural Imperialism New York, St. Martin's Press, 1991.
} 
enfrentavam práticas de coerção de seus trabalhos muito diferentes daquelas que afetavam a mulheres européias. Nesse sentido, argumento que os arranjos locais de trabalho sexual são tão centrais para a compreensão dos significados das histórias de tráfico de mulheres e os debates sobre o controle da prostituição em Buenos Aires e no Rio de J aneiro, como também é reconhecer a dimensão internacional de to das essas histórias.

$\mathrm{Na}$ primeira parte do artigo, examino brevemente alguns momentos dos debates sobre a regulamentação da prostituição em Buenos Aires e no Rio de Janeiro. Em ambas cidades, a intervenção estatal sobre relações domésticas era vista com desconfiança e resistência. Mas as políticas públicas sobre a prostituição tomaram cominhos muito diferentes. No Rio, a crise do trabalho escravo parece haver sido um fator crucial que impediu a regulamentação da prostituição, conferindo significados específicos aos debates regulamentaristas. Enquanto isso, em Buenos Aires, o eixo da discussão da regulamentação envolvia eficazes argumentos a seu favor, ora como uma medida "moderna" e européia, ora como uma medida calcada no caráter latino dos argentinos, o que justificaria seu perfil autoritário.

Algumas modalidades de trabalho sexual vigentes nas duas cidades em fins do século XIX são brevemente discutidas na segunda parte. Enquanto médicos e homens da lei discutiam a regulamentação da prostituição como medida profilática e moralizante, e começavam a preocupar-se com 0 tráfico de mulheres brancas, a maior parte das prostitutas nas janelas das ruas centrais do Rio eram de escravas negras, e em Buenos Aires uma quantidade de crianças argentinas eram "conchavadas" por seus pais em casas de prostitutas - ou seja, eram "alugadas" por pagamentos mensais, às vezes aos pais ou responsáveis, às vezes às próprias meninas. Não são as experiências mais típicas nem ilustrativas de trabalho sexual, mas iluminam práticas que envolviam mulheres nacionais, escravas, negras e crianças. Suas vidas dimensionam a coerção e as margens de liberdade possíveis em suas experiências de trabalho. Nas décadas seguintes, essas 
Lavar, passar e receber visitas

experiências contribuirão para moldar os significados sociais da imigração de mulheres européias.

\section{Peculiaridades sul-americanas}

Buenos Aires amargou uma indesejada fama internacional como um dos principais centros mundiais de tráfico de mulheres européias até bem entrado o século XX. A má fama também afetava o Rio, fosse como uma escala dos traficantes ou como um ponto de chegada alternativo. Mas a reputação portenha sempre superou a carioca. Sem poder ser atribuída a características geográficas (pela localização do Rio a meio caminho entre Buenos Aires e a Europa), a consolidação dessas famas diferenciadas foi decorrência de políticas públicas de controle do comércio sexual adotadas em cada cidade. Em Buenos Aires, sucessivas ordenanças municipais regulamentando o exercício da prostituição foram aprovadas a partir de 1875, fundamentadas em argumentos higiênicos e morais. Como outros países que se inspiraram no chamado modelo francês de regulamentação, a municipalidade portenha criou um status legal diferenciado para as prostitutas públicas, definindo regras para sua circulação pela cidade, assim como horários e condições de trabalho e moradia. ${ }^{8}$ Já na corte imperial brasileira, embora o tema da regulamentação municipal da prostituição chegou a ser debatido entre os ministros do Conselho de Estado, nunca houve consenso sobre a pertinência de sua aplicação.

Tanto na Argentina como no Brasil, médicos, advogados e políticos se dividiam entre "regulamentaristas" e "abolicionistas". Mas os debates sobre as políticas públicas sobre a prostituição estavam longe de reduzir-se a posturas antagônicas. Tanto 0 debate internacional como as políticas postas em prática

${ }^{8} 0$ "sistema francês" era um estilo de regulamentar a prostituição herdado das leis napoleônicas do começo do século XIX. Com muitas mudanças, persistiu ao longo do século, sendo adotado em muitos outros países. Corbin, Alain. Women for Hire... Op. cit. 
compreendiam uma ampla gama de formas e intensidades da intervenção estatal sobre o comércio sexual. Em um momento em que os discursos higienistas se configuravam como ideologias, justificando a intervenção pública, científica e técnica em relações privadas e domésticas, ninguém pensavam em deixar o comércio sexual de fora. Mas não havia consenso sobre os limites de tal intervenção. 0 debate internacional se concentrou, sobretudo, no sistema francês, que previa reclusão de prostitutas em "casas de tolerância" e exames médicos periódicos obrigatórios, além da internação forçada das doentes venéreas. Aqueles que questionavam esse sistema, tanto no continente americano como no europeu, defendiam ações de saúde pública e moralização social, mas sem aceitar 0 autoritarismo de medidas que não reconheciam os direitos individuais de prostitutas e que eram questionáveis em termos de profilaxia da sífilis.

$\mathrm{Na}$ Inglaterra, em particular, uma breve tentativa de regulamentar a prostituição em cidades portuárias gerou um amplo rechaço social, fundamentado não só em argumentos liberais, mas também num pensamento puritano que questionava a dupla moral sexual - base da idéia da prostituição como um "mal necessário". ${ }^{9}$ Embora nas cidades inglesas as medidas regulamentaristas acabaram sendo revogadas, elas continuaram sendo referência nas colônias inglesas e em outros países, como nos Estados Unidos. ${ }^{10}$ Mas a forte militância abolicionista no Reino Unido, junto com a ação de outros grupos reformistas e filantrópicos europeus, levou à construção de um consenso internacional sobre a relação entre a regulamentação da prostituição e o tráfico de mulheres. ${ }^{11} \mathrm{~A}$ idéia de que os países

\footnotetext{
9 WALKowitz, J. Prostitution and Victorian Society... Op. cit.

${ }^{10}$ É o argumento de BRIGGS, L. Reproducing Empire... Op. cit, pp.21-41.

${ }^{11}$ Guy, Donna. El Sexo Peligroso. La Prostitución Legal en Buenos Aires. Buenos Aires, Ed. Sudamericana, 1991, pp.17-54; WALKOWITZ, J. Prostitution and Victorian Society... Op. cit.; CORBIN, A. Women for Hire... Op. cit, pp.214246; B RISTow, E. Prostitution and Prejudice... Op. cit.
} 
Lavar, passar e receber visitas

regulamentaristas, adotando idéias autoritárias e atrasadas, se transformavam em locais de tráfico ganhou tanta força, que no começo do século XX a maior parte da mobilidade internacional de mulheres européias que viajavam sós para a América do Sul tendia a ser interpretada como uma mobilidade forçada - como tráfico, não como imigração.

Essa associação entre regulamentação e tráfico explica em parte a má fama portenha, mas não explica porque Buenos Aires teve ordenanças municipais que regulamentavam a prostituição e o Rio de J aneiro não. A resistência carioca a adotálas foi amplamente atribuída à indiossincrasia do Imperador Pedro II, cujas conviç̧ões liberais e abolicionistas frearam os projetos regulamentaristas de médicos entusiastas da experiência francesa. ${ }^{12}$ Indo além da dimensão anedótica, essa explicação indica a diferença de status político de ambas cidades: enquanto Buenos Aires gozava de muito mais autonomia e força política local, o Rio de Janeiro estava submetido a um centralizado poder imperial. $\mathrm{Na}$ corte brasileira, as propostas regulamentaristas, mesmo sendo municipais, dependiam da aprovação do Imperador e seu Conselho de Estado. ${ }^{13}$ Essa diferença é central para a compreensão das medidas de controle da prostituição efetivamente implementadas em cada cidades, bem como o peso dos médicos higienistas em cada municipalidade. A higiene

\footnotetext{
${ }^{12} \mathrm{O}$ médico francês Louis Fiaux foi um dos que atribuiu a excepcionalidade do caso brasileiro ao Imperador. Segundo Fiaux, Dom Pedro II teria afirmado que "durante seu reinado, o regime da polícia de costumes não será nunca introduzida no Brasil". Fiaux, Loius. La Police des Moeurs en France et Dans les Principaux Pays de l'Europe. Paris, E. Dentu, 1888, pp.593-594. Agradeço a referência a Henrique Espada. Sobre o amplo uso dessa explicação, ver Carrara, Sérgio. Tributo a Vênus: a Luta contra a Sífilis no Brasil, da Passagem do Século aos Anos 40. Rio de J aneiro, FIOCRUZ, 1996.

${ }^{13}$ Freire, Américo. Uma Capital para a República: Poder federal e forças políticas locais no Rio de J aneiro na virada para o século XX. Rio de Janeiro, Revan, 2000, pp.25-39.
} 
ganhou foros de ideologia nas duas cidades, mas as condições políticas de implementação não foram as mesmas. ${ }^{14}$

A ausência de regulamentação no Rio de Janeiro não implicou um descaso estatal com o tema, e sim uma maior concentração das medidas de controle das prostitutas nas mãos das autoridades policiais. ${ }^{15}$ É por isso que, no começo do século $X X$, encontramos um conhecido advogado abolicionista criticando o peculiar "sistema brasileiro". Evaristo de Moraes acusava as autoridades policiais de ter uma visão "acanhada" do problema, o que criava um sistema que não podia ser definido nem como regulamentarista, nem como abolicionista. ${ }^{16} \mathrm{O}$ que ele via como falta de política era, na realidade, uma certa política que resultou de múltiplos conflitos entre autoridades policiais, prostitutas e autoridades judiciárias, e que se caracterizou por instáveis regras não escritas e por negociações locais e pontuais. Sua implementação, nas primeiras décadas republicanas, provocou a concentração de prostitutas notórias em ruas próximas ao centro da cidade, de modo não tão diferente daquele que

\footnotetext{
${ }^{14}$ A reforma urbana portenha aconteceu na década de 1880 , enquanto a carioca só nos primeiros anos do século XX. Buenos Aires teve seu primeiro sifilicômio em 1888, e no Rio pode-se dizer que não houve uma política pública de co mbate às doenças venéreas até os anos 1930. GuY, D. EI Sexo Peligroso... Op. cit., pp.104-133, MugiCA, Maria Luisa. Sexo Bajo Control: la prostitución reglamentada. Rosario entre 1900 y 1912. Rosario, UNR Ed., 2001, pp.87-117. Sobre o Brasil, Carrara, Sérgio. Tributo a Vênus... Op. cit.

${ }^{15}$ Mas conflitos com autoridades municipais eram freqüentes no caso carioca, e a polícia era uma presença evidente no caso portenho. Pereira, C. S. "Que Tenhas Teu Corpo"... Op. cit., cap. 1. Ao privilegiar a análise de fontes municipais no caso rosarino, Maria Luisa Mugica evidencia centralidade desse âmbito em contextos regulamentaristas. MugICA, M. L. Sexo Bajo Control... Op. cit., esp. pp.47-49.

${ }^{16}$ MoraEs, Evaristo. Reminiscências de um rábula criminalista Rio de Janeiro/ Belo H orizonte, Briguiet, 1989, p.84.
} 
Lavar, passar e receber visitas

predominou em cidades latino-americanas que adotaram sistemas regulamentaristas. ${ }^{17}$

Já o regulamento portenho de 1875 combinava argumentos higiênicos - proteger a saúde do consumidor e salvar o futuro da nação argentina da ameaça da sífilis - com argumentos morais, mais familiares aos moradores de Buenos Aires. Assim, ao mesmo tempo em que dispunha os exames médicos obrigatórios para as prostitutas inscritas, também definia seus horários de circulação pelas ruas, a fachada de suas casas, e a localização das casas em relação a templos religiosos, teatros e escolas. O tipo de controle previsto já sugere de saída sua escassa possibilidade de implementação. Como ressaltou Donna Guy, as mulheres suspeitas de serem prostitutas clandestinas deveriam pagar uma multa à prefeitura, mas não eram obrigadas a inscrever-se; as que se inscreviam deviam submeter-se aos exames médicos, pagar impostos, além de serem tratadas como "reclusas de meio tempo".$^{18}$ Mais que moralizar ou higienizar a cidade e a nação, o regulamento criava um mecanismo de transferir o dinheiro das prostitutas para os cofres municipais. De fato, esse foi um dos principais eixos do conflito entre autoridades municipais, policiais, as donas das casas de prostituição, e as próprias prostitutas. ${ }^{19}$

Ao mesmo tempo em que participava dos debates internacionais sobre as políticas sobre a prostituição, a ordenança portenha de 1875 era parte também dos debates públicos na Argentina sobre práticas de coerção do trabalho. A obrigatoriedade de uma carteira de identidade para as prostitutas não deixava dúvidas sobre a dimensão da ordenança como um mecanismo de regular o trabalho sexual feminino. Neste aspecto,

${ }^{17}$ GuY, D. El Sexo Peligroso... O p. cit; um padrão semelhante de conflito s entre diferentes autoridades e de concentração espacial da prostituição também ocorreu em Montevidéu. TROCHON, Yvette. Las Mercenarias del Amor. Prostitución y Modernidad en el Uruguay (1880-1932). Montevideo, Santillana, 2003.

${ }^{18}$ GUY, D. El Sexo Peligroso... Op. cit., p.69.

${ }^{19}$ ID., IB. 
a exigência da carteira ecoava os recorrentes esforços estatais, ao longo do século XIX, para controlar a mobilidade dos trabalhadores argentinos. Em meio aos primeiros anos de vigência da ordenança, uma quantidade de mecanismos mais amplos de coação ao trabalho estavam sendo implementados e ao mesmo tempo questionados. ${ }^{20}$ Enquanto certas medidas pareciam ser socialmente mais aceitas, embora consideradas violentas e autoritárias, como a oficialização de um status legal específico para as prostitutas, outras eram mais questionadas, como o respaldo estatal a certas práticas de exploração de seu trabalho, na medida em que as ordenanças reconheciam a figura da "regenta".

O debate sobre coerção ao trabalho está presente no principal pressuposto do texto da ordenança de 1875: a prostituta que se inscreve seria uma pessoa livre, maior de idade, autônoma, que decide, por livre e espontânea vontade, colocar-se sob o domínio das leis municipais. Por isso, a ordenança exigia que, para serem registradas, as prostitutas deveriam "ser maiores de 18 anos, a não ser que se prove que antes dessa idade tenham se entregado à prostituição". Maiores de idade ou não, o fundamental era que asa mulheres inscritas tivessem desistido, por sua livre vontade, de sua honestidade sexual e, portanto, da proteção do Estado a esse respeito. Ninguém acreditava que as

\footnotetext{
${ }^{20}$ Sobre a grande mobilidade que caracterizava a classe trabalhadora argentina no século XIX, Salvatore, R. Wandering Paysanos: State Order and Subaltern Experience in Buenos Aires During the Rosas Era. Durham, Duke University Press, 2003, pp.61-69; sobre a implementação e o questionamento de leis de conchavo em Tucumán, Bravo, Maria. Liberales, socialistas, Iglesia y patrones frente a la situación de los trabajadores en Tucumán. In: SURIANo, J. (org.) La Cuestión Social en la Argentina, 1870-1943. Buenos Aires, La Colmena, 2000, p.32. Um dos questionamentos a certas práticas coercitivas foi a greve de empregadas domésticas contra a libreta de conchavo, em 1888, apud LoBATo, M. Entre la protección y la exclusión: discurso maternal y protección de la mujer obrera, Argentina 1890-1934. In: SURIANo, J . (org.) La Cuestión Social... Op. cit., p.247; SÁbato, H. e Romero, L.A. Los Trabajadores de Buenos Aires. La experiencia del mercado, 1850-1880. Buenos Aires, Sudamericana, 1992, pp.188-190.
} 
Lavar, passar e receber visitas

prostitutas inscritas o fizessem por decisão própria, mas a necessidade de escrever essa espécie de ficção legal revela os limites da aceitação social de certas práticas de coerção.

Numa das muitas propostas de reforma da ordenança de 1875 , os limites dessa ficção ficavam patentes. Passada quase uma década da primeira ordenança, já em 1887, um médico portenho entusiasmado com as idéias neo-regulamentaristas de A. Fournier explicitava em sua proposta de reforma do texto original que: "Nenhuma mulher pode permanecer contra a sua vontade numa casa de prostituição e bastará indicá-lo ao inspetor que visite a casa para que seja atendida em seu pedido pela polícia". ${ }^{21}$ Além de sugerir as críticas que choviam sobre os regulamentaristas naquele momento, o texto sugere uma crescente dificuldade social em aceitar certas práticas de coação sobre prostitutas. Por isso, este autor considerou importante aperfeiçoar a ficção original.

Era difícil, porém, encontrar vozes em Buenos Aires que se levantassem contra as medidas regulamentaristas. A maior parte dos médicos e juristas argentinos parecia considerar aceitável, e até inevitável, uma certa dose de coação na regulamentação implementada em países latinos. 0 próprio médico que propôs a reforma de 1887 considerava conveniente buscar nos exemplos europeus um modelo adequado aos "nossos costumes e legislação".22 Como ele, muitos outros homens da ciência pareciam acreditar que, por mais que a Argentina estivesse a caminho da civilização, não se podiam ignorar certos "costumes" locais. O de "vender e rifar" jovens mulheres, que nos anos seguintes seria denunciado como uma marca dos traficantes estrangeiros de prostitutas, em 1887 era definido como uma

\footnotetext{
${ }^{21}$ Ao associar sífilis e degeneração, o médico Alfred Fournier se tornou o principal representante do "neo-regulamentarismo". CARRARA, Sérgio. Tributo a Vênus... Op. cit., pp.61-64. O autor da proposta de 1887 foi RAmIREZ, Eugenio. Profilaxia Pública de la Sífilis. Reformas Urgentes a la Reglamentación de la Prostitución. Estudios de H igiene Social. Buenos Aires, El Censor, 1887, p.149.

${ }^{22}$ RamiRez, E. Profilaxia Pública de la Sífilis... Op. cit., p.173.
} 
prática "eminentemente criola". ${ }^{23}$ A venda de mulheres era associada, primordialmente, a formas não assalariadas e não contratuais de trabalho que caracterizaram diferentes modalidades de serviço doméstico no século $X I X{ }^{24}$ Diante da persistência dessas práticas, certo autoritarismo estatal era até recomendável. "Nossos costumes e legislação" não eram feridos com a violência da regulamentação.

Este tipo de ponderação era tão eficaz que permeava até o pensamento dos abolicionistas. Algumas décadas depois, um jovem advogado, convencido de que o regime das casas de tolerância estava com seus dias contados, considerava improvável que "se chegasse a aceitar, por agora", as idéias abolicionistas na Argentina. Para ele e muitos de seus colegas, já havia uma verdadeira cultura regulamentarista arraigada entre os portenhos nos primeiros anos do século XX. ${ }^{25} \mathrm{Em} 1907$, outro abolicionista opinava com cautela a favor da manutenção da regulamentação, que ele definia como um sistema "compenetrado com o costume e com a tradição, que se harmoniza com a índole do nosso povo, com o grau de cultura em que nos encontramos, e até com as condições étnicas e psíquicas da própria raça, em suas derivações de índole moral". ${ }^{26}$ Por mais que concordassem com as críticas médicas e morais à regulamentação e que condenassem sua dimensão coercitiva e violenta, havia uma grande dificuldade entre douto res e outros homens ilustrados argentinos em substituir um sistema afinado aos "costumes e tradições" pelos resultados de "distantes congressos científicos". ${ }^{27}$ Se 0 tráfico de mulheres era

\footnotetext{
${ }^{23}$ ID., IB., P.111.

${ }^{24}$ Sábato, H. e Romero, L.A. Los Trabajadores de Buenos Aires... Op. cit., p. 185.

${ }^{25}$ Gálvez, Manuel. La Trata de Blancas. Tesis presentada para optar al grado de do ctor en jurisprudencia. Buenos Aires, Imprenta de J osé Tragant, 1905, p.85.

${ }^{26}$ LAmAS, Carlos Saavedra. Estudio Sobre la Prostitución en Buenos Aires Buenos Aires, s./ed., 1907, p.65.

${ }^{27}$ ID., IB.
} 
Lavar, passar e receber visitas

considerado um "câncer da civilização", um sintoma negativo da modernidade, era no passado e na tradição que esses autores se apoiavam para defender a regulamentação do comércio sexual. ${ }^{28}$

Entre as peculiaridades argentinas que justificavam a regulamentação do comércio sexual, estava também a tradição legal que não reconhecia o delito de proxenetismo, fosse como a indução de uma mulher à prostituição ou como a obtenção de lucros com a prostituição de terceiros. Na tradição legal latina da qual a Argentina era parte, o proxenetismo foi, por muito tempo, parte do delito de "corrupção de menores". Em outras palavras, a justiça só intervia na exploração de uma prostituta quando se tratava de uma mulher considerada legalmente incapaz (como as menores de idade), o que estava de acordo com a tal ficção regulamentarista de que a prostituta que se inscreve o faz por sua livre vontade. Era atribuição do Estado proteger as mulheres que ainda não estivessem "perdidas", enquanto que as outras deveriam ser controladas para a proteção da sociedade. Só em 1913 os legisladores argentinos debateram a "lei Palácios", que previa a "repressão da corrupção de mulheres". Pela primeira vez, se reconhecia que não só as menores de idade, mas qualquer mulher poderia ser "corrompida" com "violência, ameaças, abuso de autoridade ou qualquer outro modo de intimação". ${ }^{29} \mathrm{~A}$

\footnotetext{
${ }^{28}$ Sobre a associação entre prostituição e modernidade na Argentina, Masiello, FRANCINE. Entre Civilización y Barbarie: mujeres, nación y cultura literaria en la Argentina Moderna. Ro sario, Beatriz Viterbo Ed., 1997, pp.151-160. A referência ao tráfico de mulheres como câncer da civilização é do debutado Arturo Bas no debate da lei Palacios, apud Feinmann, Enrique. Policía Social. Estudios Sobre las Costumbres y la Moralidad Pública. Buenos Aires, Imprenta y Enc. de la Policía, 1913, p.43.

${ }^{29}$ Feinmann, E. Policía Social... Op. cit., p.39. A novidade da idéia era patente até na maneira de nomear o delito - como corrupção de mulheres -, que seguia com a denominação do que era reconhecido como criminoso - corrupção de menores. No Brasil, a corrupção de menores e lenocínio eram delitos diferenciados desde o Código Penal de 1890. Siqueira, Galdino. Direito Penal Brasileiro. Parte Especial. Rio de J aneiro, Jacinto Ribeiro dos Santos, 1924, p.488.
} 
dificuldade em reconhecer oficialmente a coação sobre uma mulher de maior idade contrastava com a crescente circulação de um vocabulário que se referia às experiências de prostituição feminina através de metáforas de escravidão. Além disso, também contrastava com uma variedade de mecanismos de coação ao trabalho sexual comuns em Buenos Aires de fins do século XIX.

Em muitos aspectos, a situação era bem diversa no Rio de J aneiro. Numa cidade em que a maior parte do trabalho era associado à escravidão, reconhecer que uma mulher de maior idade podia ser coagida ao trabalho sexual não era nada difícil. $\mathrm{N}$ as teses médicas sobre prostituição que começaram a aparecer em meados do século XIX, a prostituição recorrentemente associada à escravidão. Os jovens autores dessas teses defendiam algum tipo de regulamentação, considerando, de modo similar a seus pares portenhos, que as prostitutas, escravas ou livres, eram ameaças sociais. Mas se olharmos para fora dos claustros da Faculdade de Medicina, o que se nota - especialmente quando se evoca, por contraste, o caso portenho - é a ausência de implementação dos projetos desses doutores, num panorama que não mudaria até bem entrado o século XX. Para compreender os sentidos dessa ausência, dois momentos da década de 1870 são esclarecedores: a campanha pela liberdade das escravas prostitutas, em 1871, e a discussão de um projeto de regulamentação municipal da prostituição no Conselho de Estado, em 1877. Ambas ocasiões sugerem os limites da repercussão do pensamento dos jovens médicos na sociedade brasileira e ao mesmo tempo marcam o processo pelo qual a prostituição se transformou em objeto de políticas públicas. ${ }^{30}$

A questão das prostitutas escravas em 1871 foi utilizada por dois historiadores para interpretar os debates políticos sobre o

\footnotetext{
${ }^{30}$ A histo riadora Sandra G raham alertou para a necessidade de contextualizar a repercussão social dos projetos médicos. Ver GRAHAM, Sandra. Dangerous fantasies: the altered vocabulary of commercial sex. Luso-brazilian review, 30 (1), Wisconsin, 1993.
} 
Lavar, passar e receber visitas

futuro das relações de trabalho no Brasil.. ${ }^{31}$ Em setembro daquele ano, depois de duros debates parlamentares, foi aprovada a lei do ventre livre. A lei ganhou fama por libertar os filhos de escravas nascidos a partir daquela data. Mas seu outro aspecto crucial, como mostrou Sidney Chalhoub, foi o reconhecimento formal dos direitos dos escravos ao pecúlio e a comprar sua própria liberdade a seus senhores. Embora essa prática já fosse comum (e os senhores não costumavam negar-se a ela), o registro desse direito na letra de lei significava o reconhecimento de que a liberdade não dependia da vontade senhorial para se concretizar. Foi nesse sentido que a lei do ventre livre foi um duro golpe nas bases da ordem senhorial. Por outro lado, ela também foi um esforço por parte dessa mesma classe senhorial para manter seu controle e autoridade sobre a crise das relações de trabalho em curso, especialmente ao garantir a prestação de serviços por parte dos libertos, fosse como indenização (no caso das crianças libertadas pela lei), fosse para pagar a dívida contraída na compra da liberdade. ${ }^{32}$

A iniciativa de um delegado do centro da cidade, que em 1870 concentrava a maior parte da prostituição visível, se inscreve nesse debate. Com uma lista das escravas de que exerciam a prostituição naquelas ruas, o delegado Miguel Tavares iniciou ao redor de 200 ações de liberdade, com base no princípio do direto romano que dispunha que forçar escravas à prostituição justificava a perda da propriedade. Em seu relatório ao chefe de polícia, Tavares descrevia com detalhe a triste situação daquelas mulheres. Elas "prostituem o coração e o sentimento mais íntimo e puro - o do recato e pudor, a que tem direito toda mulher, ainda que seja

\footnotetext{
${ }^{31}$ Chalhoub, Sidney. Visões da Liberdade: uma história das últimas décadas de escravidão na corte São Paulo, Cia. das Letras, 1990,151-161 e GRAHAM, S. Slavery's impasse: slave prostitutes, small-time mistresses, and the Brazilian Law of 1871, Comparative studies in so ciety and history, 33 (4), Ann Arbor, MI, 1991, pp.669-694.

${ }^{32}$ Chalhoub, S. Visões da Liberdade... Op. cit., pp.151-161.
} 
escrava" ${ }^{33} \mathrm{~A}$ intervenção da autoridade pública numa relação até então considerada privada, entre o senhor e sua escrava, era justificada quando essa relação, por sua imoralidade, ameaçava a própria natureza feminina. Entretanto, o que as ações de liberdade de 1870 indicam é que longe de gerar unanimidade, tal intervenção era uma verdadeira arena de disputas. Isso se nota tanto com a dificuldade de se encontrar advogados para as escravas e como pelas sentenças favoráveis que alguns senhores conseguiram. A historiadora Sandra Graham argumenta que o próprio Tavares não era um abolicionista, mas buscava "moralizar" a sociedade, no sentido de preservar a autoridade moral. Deste modo, é significativo que suas ações não tenham sido dirigidas às prostitutas mesmas - como ocorreria, por exemplo, com as indicações médicas de regulamentação - e sim aos senhores de escravas que não se comportavam como deviam. $\mathrm{Na}$ realidade, esses "senhores" eram em sua maioria mulheres brasileiras e portuguesas sem muitos recursos, denominadas por Sandra Graham como o "elo mais frágil" do poder senhorial. Por conta disso, elas podiam ser punidas sem que isso fosse visto como uma grande ameaça à ordem social. ${ }^{34}$

Foi, assim, em meio aos debates sobre o futuro das relações de trabalho que a prostituição se transformou num assunto da incumbência do Estado no Brasil. Por um lado, como se verá adiante, isso favoreceu a que as escravas prostitutas recorressem à polícia e aos tribunais em busca de proteção contra abusos, e especialmente, de liberdade. Por outro lado, essa situação levou ao fortalecimento da associação entre escravidão e prostituição, tornando cada vez mais impensável que o Estado assumisse o papel de "senhor" das prostitutas, regulamentando seu trabalho. A reticência e a cautela que caracterizaram os debates do período

${ }^{3}$ Ofício de Miguel Tavares ao Chefe de Polícia, reproduzido no seu relatório ao Ministro da J ustiça. MINISTÉRIO DA J USTIÇA. Relatório da Repartição dos Negócios da J ustiça apresentado à Assembléia Geral Legislativa. Rio de Janeiro, Imprensa Nacional, 1871.

${ }^{34}$ G RAHAM, S. Slavery's impasse... Op. cit., pp.669-694. 
Lavar, passar e receber visitas

sobre a prostituição - as mesmas reticência e cautela dos debates sobre o fim do trabalho escravo - se tornam, assim, mais compreensíveis. ${ }^{35}$

Passados seis anos da campanha das escravas prostitutas, e dois anos depo is que Buenos Aires aprovou a primeira ordenança regulamentando o comércio sexual, a Câmara Municipal do Rio de Janeiro votou um projeto de regulamentação "das casas de tolerância". Considerado um tema "dos mais delicados que se tem apresentado ao Governo Imperial para sobre ele deliberar" pelo funcionário da Secretaria de Estado dos Negócios do Império, a regulamentação foi cautelosamente rechaçada pelos membros do Conselho de Estado. ${ }^{36} \dot{A}$ semelhança da ordenança portenha, nesse projeto eram estabelecidos exames médicos obrigatórios para as "mulheres públicas inscritas", horários e condições para sua exposição pública, e se responsabilizava as "diretoras de tais casas" pelas multas em casos de infrações. De modo diferente da ordenança portenha, a polícia tinha a prerrogativa de implementar o registro de prostitutas, estendendo as obrigações das inscritas "a qualquer outra casa em que haja mulher pública". Além disso, um de seus artigos proibia os senhores de "consentir" que suas escravas vivessem da prostituição, o que sugere que a campanha de 1871 não foi suficiente para abolir essa prática.

Apresentaram pareceres 0 secretário de Estado dos Negócios do Império, as seções reunidas dos N egócios do Império e Justiça do Conselho de Estado, e o Barão do Lavradio, que além de conselheiro era também presidente da J unta Central de Higiene. Todos foram favoráveis ao rechaço das posturas que "reconhecem e regulamentam as casas de tolerância", concordando que a figura das casas de tolerância, "escolas de

\footnotetext{
${ }^{35}$ Chalhoub, S. Visões da Liberdade... Op. cit.; Mendonça, J oseli. Cenas da Abolição: escravos e senhores no Parlamento e na Justiça. São Paulo, Fundação Perseu Abramo, 2001.

${ }^{36}$ Conselho de Estado, Seção do Império, "Consulta e Parecer Sobre o Projeto de Postura Relativo a Casas de Tolerância". Caixa 555, Pac.3, Doc.3, 1877. (Arquivo Nacional, Rio de J aneiro).
} 
desmoralização e do crime", não deveriam ser regulamentadas, e sim combatidas. $^{37}$ Isso não significava que estes homens se opusessem à prostituição; ao contrário, como ocorria em Buenos Aires, todos a consideravam necessária. 0 que condenavam era a versão francesa da regulamentação, o sistema das "casas de tolerância" em que as mulheres viviam sob a vigilância da regenta e do Estado. Em seu lugar, sugeriram medidas como a de não aceitar casas de prostituição com mais de duas mulheres, "para que não fique configurado que uma vive da outra". ${ }^{38} \mathrm{Um}$ deles chegou a se apoiar no exemplo do regulamento belga, uma das inspirações da ordenança portenha, para propor que as casas de prostituição se concentrassem fora do centro da cidade e longe de estabelecimentos religiosos e de educação. Recorria também à breve experiência regulamentarista inglesa para defender a obrigatoriedade do exame médico de prostitutas. ${ }^{39}$ Essa menção de exemplos regulamentaristas europeus em meio a uma argumentação abolicionista reforça a idéia de que, na prática, as posições não eram tão polarizadas. Ninguém questionava a necessidade de intervenção do Estado, e sim sua forma e extensão. 0 eixo do debate era até onde o Estado podia ir sem invadir relações sociais de âmbito privado, especialmente as que estavam sob um forte debate, como entre senhores e escravas.

0 Barão do Lavradio seguia o mesmo tom, opondo-se à existência das "casas de tolerância", mas considerava necessário "um regulamento policial severo" que dispusesse sobre a localização das casas e a exposição das prostitutas. ${ }^{40} \mathrm{~J}$ á as "seções reunidas" expressaram a crítica mais severa à regulamentação e seus efeitos nos países europeus. As seções questionaram a

\footnotetext{
${ }^{37}$ J esuíno Ferreira, Secretaria de Estado dos Negócios do Império, Conselho de Estado, Consulta e parecer... Op.cit., p.4.

${ }^{38}$ ID., IB., p. 5.

${ }^{39}$ ID., IB., pp.6-7.

${ }^{40}$ Barão do Lavradio, Conselho de Estado, Consulta e parecer... Op.cit., pp.810.
} 
Lavar, passar e receber visitas

eficácia dos exames médicos obrigatórios para combater a sífilis, assim como a inscrição de prostitutas para evitar a ação dos proxenetas. Reforçando a associação entre regulamentação e tráfico, afirmaram que nos países que adotavam o sistema regulamentarista se especulava com jovens honestas "como se especula com mercadorias". ${ }^{41} \mathrm{Em}$ meio à intensificação dos debates sobre o fim da escravidão, a intervenção estatal para sancionar a exploração do trabalho sexual de uma prostituta era considerada por todos os consultados como escandalosa. Mas essa postura não implicava recusar a vigilância moral sobre o comércio sexual. Assim, todos os defenderam com veemência outras medidas de vigilância, que iam desde localizar as prostitutas em certas partes da cidade, até a ampliação das atribuições da polícia. Em suma, a precaução frente ao "delicado" tema da prostituição contrasta com a decisão e o consenso para condenar o sistema das casas de tolerância e a prostituição de escravas. Sobre esse último assunto, um dos consultados chegou a afirmar que "se eu não temesse os abusos, exigiria mais rigor sobre 0 assunto desta disposição, punindo a tolerância criminosa dos senhores com a liberdade das suas escravas". ${ }^{42}$ Mas 0 arrebato abolicionista desse funcionário era contido pelo seu temor, e o de seus contemporâneos, frente à instabilidade social que percebiam ao seu redor. No mesmo sentido, as seções ressaltavam o difícil que seria submeter a exames obrigatórios às prostitutas clandestinas. Sendo em sua maioria escravas, e vivendo no "lar das famílias", tais mulheres não poderiam ser inscritas e inspecionadas "sem grande alarme e resistência". ${ }^{43}$ A precaução generalizada se relacionava, por um lado, como o perigo que representava a intervenção do Estado no âmbito das relações de trabalho. Por outro, evidenciava a relutância estatal em legitimar a exploração do trabalho sexual por terceiros. Nesse sentido, o

\footnotetext{
${ }^{41}$ Seções, Conselho de Estado, Consulta e parecer... Op.cit, pp.11-17.

${ }^{42}$ J esuíno Ferreira, Conselho de Estado, Consulta e parecer... O p. cit., p.6.

${ }^{43}$ Seções, Conselho de Estado, Consulta e parecer... Op. cit., p.16.
} 
comentário do abolicionista francês Louis Fiaux sobre a peculiariedade do caso brasileiro ganha ressonância. Comentando a recusa brasileira em regulamentar, Fiaux citava a explicação de um funcionário público brasileiro, segundo o qual o Imperador Pedro II era pessoalmente contrário a "toda medida coercitiva nessa matéria". ${ }^{44}$ A percepção da regulamentação como uma medida essencialmente coercitiva, mais que moralizadora ou higiênica, parece ter sido a interpretação predominante entre os funcionários imperiais. Em meio a tanta resistência, o Conselho de Estado terminou por recomendar "deixar as coisas como estavam".

As peculiariedades sul-americanas dos debates sobre a regulamentação da prostituição se tornam mais visíveis à luz das relações de trabalho predominantes em cada cidade. Em Buenos Aires, a regulamentação tinha simultaneamente uma dimensão moderna, na medida em que o Estado, seguindo o exemplo das nações européias, começava a intervir nas relações sociais domésticas, e uma dimensão mais "peculiar", na medida em que o autoritarismo e a violência que tal intervenção envolvia eram justificados com base na "tradição e costumes" das relações de trabalho argentinas. Por sua vez, a "peculiaridade" brasileira da escravidão e do espectro de relações sociais domésticas que ela gerou era um dos principais fatores que diferenciava o caso carioca do portenho. No Rio de J aneiro, a intervenção estatal no comércio sexual significava necessariamente uma intervenção numa ordem social instável e na hierarquia que essa ordem implicava. Argumentos morais e higienistas estavam presentes nos dois casos, mas justificavam posições bem diferentes. Em ambos casos, os debates sobre a regulamentação esclarecem um amplo espectro de relações sociais e arranjos de trabalho doméstico e sexual.

${ }^{44}$ FIAUX, L. La Police des Moeurs...op.cit., 593-594. 
Lavar, passar e receber visitas

2. A vida de "receber visitas"

Enquanto as histórias de tráfico de mulheres associavam a coerção ao trabalho sexual feminino com a experiência de prostitutas européias emigradas para o continente americano, jovens argentinas e brasileiras se viam envolvidas numa ampla gama de práticas de trabalho doméstico e sexual. Os registros dessas experiências de trabalho revelam 0 status legal da prostituição em cada cidade, ao mesmo tempo em que indicam as características da ação judicial sobre a exploração sexual em ambos casos, em particular os limites da intervenção estatal em relações de poder domésticas. Em Buenos Aires, a regulamentação convivia com uma tradição legal em que o proxenetismo não era tratado como um delito à parte, mas como parte da figura penal da "corrupção de menores". Já no Rio de Janeiro, os homens públicos se viram obrigados a discutir a exploração das prostitutas, maiores ou menores de idade, por terceiros.

Mesmo antes da aprovação do Código Penal argentino, em 1886 , os processos criminais sobre a exploração de prostitutas em Buenos Aires definiam o delito como "admitir uma menor em seu lupanar", "sequestro de menor", ou "sedução" - diferentes expressões que confirmavam que o crime não era a exploração sexual de qualquer mulher, e sim de menores de idade. No Rio de Janeiro, o Código Penal republicano (1890), consolidou outra maneira de tratar a exploração do trabalho sexual de mulheres. Ao não regulamentar a prostituição, as leis brasileiras consideravam que qualquer mulher, maior ou menor de idade, "honesta" ou prostituta, era passível de ser sexualmente explorada. ${ }^{45}$ Mesmo antes do Código, encontramos uma variedade de situações em que a indução ou exploração do trabalho sexual feminino eram condenadas. Entre elas, estão as ações de liberdade a favor das prostitutas escravas. Outro exemplo

\footnotetext{
${ }^{45}$ Sobre a legislação republicana, SIQUEIRA, Galdino. Direito Penal... Op. cit.
} 
são as práticas administrativas da polícia de expulsar estrangeiros acusados de lucrar com a prostituição de mulheres, fosse através de aluguéis abusivos ou outras relações de dependência com prostitutas. ${ }^{46}$

As práticas penais em ambos países revelam acordos e práticas de trabalho sexual e doméstico que surpreendem pelos seus pontos em comum: a pouca diferenciação da prostituição em relação a outros tipos de trabalho doméstico e a recorrência de práticas coercitivas semelhantes sobre mulheres e crianças. A pesar desses pontos em comum, se destacam diferenças no que se refere às possibilidade de recorrer ao Estado e aos mecanismos judiciais em situações conflitivas.

A interseção entre trabalho doméstico e prostituição aparece com freqüência nos processos de corrupção de menores em Buenos Aires, já que a maioria dos casos identificados envolvia meninas "conchavadas" pelos seus pais para realizar tarefas domésticas em casas que, posteriormente, revelavam ser de prostituição. Essa prática de "conchavar" filhas bem podia ser um dos "costumes" locais a que se referiam os autores argentinos que discutiam a regulamentação. Alguns historiadores argentinos sugerem que o serviço doméstico, identificado socialmente com o trabalho escravo e com relações paternalistas, foi considerado como um âmbito de persistência de práticas coercitivas. ${ }^{47}$ Nesse sentido, os processos de corrupção de menores sugerem que, na prática, a prostituição podia ser parte dessas práticas "tradicionais" de trabalho doméstico e infantil.

\footnotetext{
${ }^{46}$ Sobre expulsões de cáftens estrangeiros, MenESES, Lená Medeiros de. Os Indesejáveis: desclassificados da modernidade. Protesto, crime e expulsão na Capital Federal (1890-1930). Rio de J aneiro, EdUERJ , 1996.

${ }^{47}$ SÁbato, H. e Romero, L.A. Los Trabajadores de Buenos Aires... Op. cit. A persistência dessas práticas no século XX se nota nas prisões para crianças. GUY, D. Niñas en la cárcel. La Casa Correccional de Mujeres como instituto de socorro infantil. In: PITA, V.; LoZANO, F.G. e INI, M. G. (org.) Historia de las Mujeres en la Argentina, Siglo XX. Buenos Aires, Taurus, 2000, pp.25-45.
} 
Lavar, passar e receber visitas

Alheios aos debates que levaram à regulamentação municipal da prostituição, os pais das irmãs Luisa, de 9 ou 10 anos, e Rosa, de 8 anos, "conchavaram" as meninas na casa da modista francisa J uana Aurian, em $1875 .{ }^{48} \mathrm{O}$ acordo, como tantos outros no século XIX, era que as meninas ficariam na casa da francesa "na qualidade de serventas", em troca de "cem pesos mensais de salário". Por aquela época, vender o trabalho doméstico de meninas por um salário para os pais era uma prática tão comum que o próprio Defensor de Menores funcionava como uma espécie de agente de empregos, promovendo o encontro entre empregados e empregadas. ${ }^{49}$ A situação dos pais das meninas só se complicou quando uma delas contou ao Defensor de Menores que foi obrigada a "permanecer com um indivíduo num quarto totalmente a sós, trancando-a e elogiando-a com ofertas de presentes e de um salário maior se cedesse aos propósitos desonestos e criminosos daquele indivíduo". A modista Juana confirmou ao Defensor de Menores que uma das meninas estava em sua casa para "lavar e passar a roupa e o resto do serviço da casa e a outra para cuidar de uma criança". J uana explicava que a mais velha recebia visitas era por tê-lo "implorado" a Juana.

Casos parecidos aparecem na segunda metade do século XIX. Assim, já em 1891, J osefina, de 10 anos, foi conchavada na residência de um casal para realizar trabalhos domésticos e "ajudar a sustentar sua família", para o que sua mãe receberia 10 pesos mensais. ${ }^{50}$ Nos primeiros dias, Josefina explicou ao

\footnotetext{
${ }^{48}$ J uana Auriau, legajo A, no 1, 1875, Tribunal Criminal, Archivo General de la Nación, Buenos Aires (AGN). Esse caso também foi analisado por QUAGLIA, M. D. Corrupción y prostitución infantil en Buenos Aires (1870-1904). Una aproximación al tema. In: Moreno, J. L. (org.) La Política Social Antes de la Política Social. Buenos Aires, Trama Editorial/Prometeo Libros, 2000, pp.205223.

${ }^{49}$ Szuchman, M. Order, Family and Community in Buenos Aires, 1810-1860. Stanford, Stanford University Press, 1988, pp.68-70.

${ }^{50}$ Victoria Cabard, Legajo C, $n \circ$ 60, 1891, Tribunal Criminal, AGN.
} 
Defensor d eMenores, "mandaram-na lavar pratos". Mas depois, a obrigaram a arrumar-se e a "receber visitas" de homens "que faziam doer em seus órgãos genitais". Os clientes pagavam 10 pesos aos patrões de J osefina por cada encontro com ela. 0 debate judicial que caracterizou esse tipo de processo se concentrou em torno de quem era o responsável sobre essas meninas - se os pais que as conchavaram, os patrões que descuidaram sua vigilância, ou a justiça, que deveria proteger sua honestidade ameaçada. Diante de uma prática tão socialmente difundida como a do conchavo, as autoridades portenhas se viam numa situação difícil se tentassem responsabilizar os pais do que poderia acontecer na casa dos patrões. No caso das irmãs em 1875, essa dificuldade é escandalosa. Examinada e questionada, a irmã mais velha, Luisa, terminou sendo ela mesma objeto do escrutínio médico e judicial. 0 médico, o Defensor de Menores, a acusada e os pais discutiram longamente sobre a honestidade e a virtude da menina, suspeita de ser "bastante inteligente", segundo o médico, e "bastante viva", de acordo com a patroa. Enquanto isso, os dois acusados de estuprá-la, descritos por Luisa como "um médico de barba loira" e "o cônsul brasileiro" não foram incomodados nem mesmo para prestar declarações. Embora o exame médico comprovasse que a menina Luisa já não era virgem, nem o próprio promotor considerou haver elementos para condenar a modista francesa.

Como esse, em nenhum outro caso dos 15 processos de corrupção de menores identificados, o poder judicial interveio para tirar as crianças da responsabilidade paterna. Em alguns casos, como o de J osefina, em 1891, eram os próprios pais que apresentavam a queixa, esperando que os mecanismos judiciais funcionassem a seu favor. Essa expectativa de que a justiça estaria do lado do pátrio poder tinha fundamentos. Em 1868, por exemplo, duas irmãs órfãs fugiram da casa de sua madrinha para um prostíbulo em Montevidéu. Capturadas, ambas declararam sobre os maltratos freqüentes da madrinha, mas mesmo assim 0 
Lavar, passar e receber visitas

juiz determinou sua devolução à mulher. ${ }^{51}$ Também em Buenos Aires, assim, certas relações de poder parecem ter ficado a salvo da crescente intervenção dos poderes públicos nas relações sociais..$^{52}$ É bem verdade que tal intervenção, no caso carioca, tinha implicações mais ameaçadoras sobre o poder senhorial. Mas isso se devia menos às intenções das autoridades públicas com seus projetos higienistas e moralizadores, do que aos usos que os escravos e seus aliados faziam da justiça e de outros recursos estatais. Os historiadores têm mostrado que, para as escravas prostitutas, assim como para outros escravos, as delegacias de polícia e os tribunais eram instâncias para recorrer frente à exploração e o abuso de seus senhores.

Tal como acontecia com as meninas conchavadas em Buenos Aires, para as escravas no Rio a prostituição se misturava a uma variedade de serviços domésticos. Em 1870, a escrava baiana Honorata, de 19 anos, declarou à polícia que, sendo alugada por sua senhora como lavadeira e cozinheira, às vezes era também obrigada a ficar na janela e "receber visitas". ${ }^{53}$ Mas as queixas de Honorata sugerem que para ela o problema principal parece ter sido a exploração exagerada, a quantidade de trabalho que se exigia dela. Afinal, anteriormente, ela já havia se empregado numa casa em que deveria "lavar e passar durante o dia e receber visitas de noite". Considerando inaceitável tamanho

\footnotetext{
${ }^{51}$ J uan Sabate, Legajo S, no 1, 1868, Tribunal Criminal, AGN.

52 Juan Suriano documenta a falta de interesse das autoridades argentinas em regular o trabalho infantil fabril em SuRIANo, J. Niños trabajadores. Una aproximación al trabajo infantil en la industria porteña de comienzos del siglo. In: Armus, D. (org.) Mundo Urbano e Cultura Popular. Estudios de Historia Social Argentina. Buenos Aires, Sudamericana, 1990. As causas de perda do pátrio poder só foram legalmente definidas em 1919. RıOS, J.C. e TALAK, A. M. La niñez en los espacios urbanos (1890-1920). In: Devoto, F. e Madero, M. (orgs.) $\mathrm{H}$ istoria de la Vida Privada en la Argentina Tomo II. Buenos Aires, Taurus, 1999, pp.154. Ver também GuY, D. Lower-class families, women, and the law in Nineteenth-Century Argentina. J ournal of Family H istory Carleston 10 (3), 1985, pp.318-330.

${ }^{53}$ A história de Honorata é contada em Graham, S. Slavery's Impasse... Op. cit.
} 
acúmulo de trabalho, Honorata se recusou a ficar naquela casa. A historiadora Sandra Graham observa, na história dessa jovem baiana, que a relação com sua senhora era marcada por uma significativa margem de autonomia. Uma vez que Ihe pagava o dinheiro do dia, Honorata podia viver como se fosse livre - com liberdade de circulação, chegou até mesmo a viver em companhia de um brasileiro. Sua senhora não lhe provia nenhum tipo de sustentação material.

No mesmo ano, a escrava J osefa, de 19 anos, entrou com uma ação de liberdade contra sua senhora, que a comprara dizendo "destiná-la ao serviço doméstico", mas terminou obrigando-a a prostituir-se. ${ }^{54}$ Por sua vez, a escrava Colombina era destinada por sua senhora a vender frutas na rua. Sua autonomia de circulação pela cidade lhe permitiu mobilizar muitas testemunhas que confirmaram nos tribunais que ela exercia a prostituição. ${ }^{55}$ Esses casos sugerem que 0 trabalho doméstico estava vinculado de várias maneiras no Rio de Janeiro, estando ambos associados à escravidão. É provável que, além de poder encontrar aliados em suas lutas por liberdade, a prostituição permitia a essas jovens mulheres uma maior possibilidade de acumular pecúlio, tal como já ocorria desde o começo do século $\mathrm{XIX} .^{56}$

Mesmo depois da abolição da escravidão, nos primeiros anos do regime republicano, ainda se podiam encontrar, nas mesmas ruas do centro do Rio, jovens baianas e afrodescendentes às janelas e portas de suas casas. Essas mulheres brasileiras continuaram recorrendo às delegacias e tribunais para acusar, por exemplo, os donos de suas casas que lhes cobravam aluguéis exorbitantes por cômodos com janelas que

\footnotetext{
${ }^{54}$ Chalhoub, S. Visões da Liberdade... Op. cit., pp.73-74.

55 ID., IB., pp.153-154.

${ }^{56}$ Esse é 0 argumento de FARIA, Sheila de Castro. Mulheres forras - riqueza e estigma social. Tempo (9), Rio de J aneiro-RJ , 2000, pp.65-92.
} 
Lavar, passar e receber visitas

davam para a rua. ${ }^{57}$ Mas a essa altura essas janelas eram cada vez mais disputadas com as prostitutas brancas e estrangeiras, que passavam a ser vistas como vítimas e escravas de outros senhores irresponsáveis, os proxenetas.

A prostituição forçada de meninas em Buenos Aires e a de escravas negras no Rio de Janeiro sugerem como as duas sociedades enfrentaram o tema da coerção ao trabalho sexual e doméstico. Evidenciando os usos do vocabulário da escravidão e uma variedade de práticas coercitivas, anteriores às histórias de escravas brancas, os debates e as experiências de trabalho brevemente examinados nessas páginas se tornam fundamentais para compreender o panorama que encontramos no começo do século XX: enquanto em Buenos Aires havia uma grande dificuldade para aprovar leis que penalizavam o tráfico de mulheres européias, no Rio vemos jovens brasileiras e estrangeiras denunciando donas de casas de prostituição e ex-amantes na polícia com a esperança de encontrar respaldo para conflitos de trabalho. A prostituição de mulheres européias foi uma novidade de grande peso político nas duas cidades. Mas "o problema da prostituição" não começou com elas. De fato, é difícil entender os significados políticos locais das histórias das mulheres brancas traficadas se não as enxergamos à luz desses antecedentes históricos que faziam do trabalho sexual e doméstico um grande problema político ao longo da segunda metade do século XIX.

\footnotetext{
${ }^{57}$ Pereira, C. S. "Que Tenhas Teu Corpo"... Op. cit., cap.1.
} 